\title{
EL PROCESO EDUCATIVO DE LOS JÓVENES EN LA NOVELA SUERTE MULANA DE MARÍA JESÚS ALVARADO
}

\author{
Djoko Luis Stéphane Kouadio \\ Université Félix Houphouët-Boigny \\ https://doi.org/10.18778/8220-195-6.23
}

\section{Resumen}

María Jesús Alvarado identifica puntos importantes del proceso educativo en Suerte Mulana mediante la necesidad de la maduración de los jóvenes a nivel físico, así como a nivel de las facultades mentales. La escritora indica que esta maduración se basa en un aprendizaje cultural que remite, a su vez, al uso tanto del cuerpo como de las facultades a través del desarrollo de la reflexión, el amor al otro y al medio ambiente. Así, el proceso educativo termina con la destrucción de las fronteras entre seres humanos de culturas diferentes.

Palabras clave: educación - jóvenes - españoles - novela - saharauis.

1.

\section{Introducción}

La presencia española en África sigue sirviendo de pretexto para abordar la cuestión de la formación y educación del ser humano mediante sus contactos con los demás. Es en este contexto que la novela contemporánea, sobre todo la de la escritora canaria María Jesús Alvarado, se dedica al análisis del comportamiento de los jóvenes en el territorio saharaui durante la colonización española. Desde entonces, ¿cómo aborda María Jesús Alvarado el fenómeno 
educativo de los jóvenes a través de su novela Suerte mulana? Nuestra hipótesis es que la novela, cuya acción tiene lugar en el territorio saharaui, sirve de tela de fondo para darle al lector orientaciones sobre el proceso educativo de los jóvenes. Basándonos en el análisis temático (Paillé, Mucchielli, 2012: 231-314), nuestro artículo empezará, primero, por la presentación de las características de Suerte Mulana. Luego, veremos el proceso de maduración de los jóvenes. Por último, hablaremos del proceso comunicativo experimental y religioso.

\section{2.}

\section{Características de la novela}

María Jesús Alvarado toma el pretexto del territorio saharaui, antigua colonia española, para explicar el proceso educativo de los jóvenes como base de la construcción de una nación (Maestre, 2003: 109-142). Su novela pone de relieve la vida de jóvenes españoles que viven en África y que tienen relaciones con los demás jóvenes saharauis. Suerte Mulana, publicada en 2002, consta de tres partes esenciales. La primera parte se titula "Poema I: Cuentos de Violeta", la segunda "Poema II: Las estrellas de Tinduf" y la tercera "Poema III: Recuerdos sobre fondo azul". Precisamos que no se trata de un conjunto de textos poéticos, sino de una novela. Sin embargo, la tipografía cambia en el capítulo "Violeta escribe al revés" porque la autora le ofrece al lector un texto en prosa cuya tipografía remite a la de los árabes. El relato basado en la vida de una joven española, Violeta, termina y empieza la segunda parte de la novela que se relaciona con la coexistencia pacífica entre jóvenes tanto saharauis como españoles. En la última parte, se lee un breve relato intimista de la vida de la novelista en el territorio saharaui; lo que da a la novela una novedad literaria como lo subraya Emilio González Déniz en el prólogo:

María Jesús Alvarado ha construido un libro hermosísimo, lirico y narrativo a la vez, contundente en su factura y muy lejos de la cursilería que suele inundar las evocaciones primerizas. Entre 
otras, es la historia de una amistad infantil, metáfora de la necesaria amistad entre dos pueblos vecinos. [...]. Ahora sé que, por fin, hay una escritora en Canarias a la que le interesa África como referente literario (Alvarado, 2002: 12-13).

La novelista no habla de la situación política de los saharauis porque prefiere proponer más bien su visión universal del fenómeno educativo por "recuerdos de su infancia saharaui" (Moya, 2011). La escritora indica que el descubrimiento de las leyes que fundamentan la sociedad y la naturaleza sirve como elemento de educación, aunque no es cosa fácil por la resistencia de los jóvenes (Pérez, 2006: 8-28). Su novela insiste en la imposibilidad de educar a alguien sin la experiencia (Montaño, Montaño, 2008: 47). De hecho, para llevar a cabo el proceso educativo, la infancia y la juventud son momentos clave para formar y educar a un individuo capaz de integrarse en la sociedad con una conciencia moral irreprochable (Tébar, 2017: 133-145). Suerte Mulana permite echar un vistazo a la importancia de la disciplina que permite el respeto de las normas sociales. Sin embargo, la autora muestra que esta formación tiene como ventaja la desaparición de las malas tendencias. Añade que la conciencia del joven está constituyéndose a lo largo de un proceso de maduración ante las realidades sociales. En efecto,

En la adolescencia, ese periodo de la vida capital en los seres humanos, se inicia el sentido histórico y la necesidad de actuar, de tomar parte de los acontecimientos, de decidir el rumbo de la propia vida. Aparecen, en consecuencia, las preguntas sobre el sentido de la existencia (¿Quién soy?, ¿adónde voy?) y se elaboran los sistemas de valores sobre los que se cimentará la personalidad adulta (Ripoll, 2006: 71).

Suerte Mulana desempeña este papel educativo. Además, mediante los sistemas de valores transmitidos por la educación, el medio ambiente se convierte en un entorno transformado en el cual surgen informaciones capitales para su bienestar. A eso, se añade la actividad práctica que permite al joven encontrar sus propias determinaciones a través de un proceso de maduración. 


\section{Un proceso de maduración}

Suerte Mulana se particulariza por la referencia a modos de aprendizaje tales como la biología, la psicología, la sociología y la historia. La referencia a estas instancias se ve en los diferentes diálogos entre el abuelo y su nieta. Es el caso del largo intercambio entre Violeta y su abuelo a propósito de la llegada de los españoles al territorio saharaui (Alvarado, 2002: 30-31). En la novela, Violeta nos aparece transformada por el entrenamiento de su cuerpo, cuando, por ejemplo, pesca con su abuelo, y su manera de pensar. Llega a dominarse en lo que concierne sus reacciones emotivas. Poco a poco, Violeta sabe lo que se puede hacer o no para ser una persona integrada en su sociedad sin considerarse como superior a los demás. Para ella, la diversidad cultural es una cosa normal porque vive en un mundo caracterizado por diferencias culturales. Otros personajes, tales como Antonio, Mulud, Bucharaya y Hassan, se convierten en portavoz de un mensaje de aceptación al otro a pesar de las diferencias o de las fronteras geográficas, políticas, culturales establecidas árbitramente por seres humanos.

Crecieron juntos. Y estudiaron juntos hasta terminar el bachiller en el instituto de El Aaiún. Eran un buen grupo, a decir de sus profesores; y eran, sobre todo, buenos amigos. Antonio [...]. Mulud. [...]. Bucharaya. [...]. Y, cuando se echan de menos, miran al cielo y saben que su amistad está a salvo por allí, muy alto, muy por encima de las fronteras, más o menos a la altura de las estrellas que comparten (Alvarado, 2002: 69-70).

La escritora lucha contra todas formas de discriminaciones y milita para que desaparezcan los perjuicios racistas que separan los seres humanos, a pesar del hecho de que viven en territorio colonial. Sin embargo, cabe señalar que Suerte Mulana no forma parte de las novelas coloniales (Carrasco, 2009) aunque la historia relatada tiene lugar en un territorio colonial ávido de libertad y nacionalismo (M'Beirik, 2015) caracterizado por una doble cultura. Es la razón por la cual la autora revela que el proceso 
educativo no excluye el reconocimiento de las potencialidades intelectuales y afectivas que caracterizan los jóvenes. Se trata del libre albedrío, la exigencia de reciprocidad y la práctica del intercambio en una sociedad de mezcla cultural. Eso convierte Suerte Mulana en una novela educativa y juvenil que participa en la socialización y la estructuración de la persona humana (Ripoll, 2006: 78). Así, los jóvenes enfrentan las vicisitudes existenciales actuales y futuras y, en el mismo tiempo, logran sus objetivos como lo revela la transformación, paso a paso, de Violeta en una joven cuya vida se aleja del racismo y de la indiferencia al otro. Mediante el caso de Violeta, el acto educativo crea las condiciones para que los jóvenes sean responsables de su propia vida abriéndose a nuevas posibilidades en un mundo globalizado (Ferronato, 2000: 11-100). Eso supone que los educadores comparten la tarea educativa no como si fueran dictadores, sino como colaboradores enseñándoles la necesidad de vivir en un universo de mestizaje (Cárdenas, 1995). Así pues, el joven admite la diferencia de culturas humanas a su alrededor. Por ejemplo, la actitud de Violeta lo indica cuando se interesa por la cultura árabe:

En cualquier caso, la grafía árabe le parecía fascinante. La combinación de líneas verticales, curvas bajas y sinuosas y puntitos estratégicamente colocados arriba y abajo, se le hacía especialmente hermosa y sugerente. Esa tarde decidió que, ya que para ella no había clases de arabía, iba a aprender a escribir español al revés, o mejor dicho, a escribirlo en el sentido correcto (Alvarado, 2002: 45-47).

Con la referencia al proceso educativo, la novelista evoca la necesidad de abordar la cuestión educativa bajo el ángulo de un rechazo del encierre de los jóvenes; técnica que hace brotar un proceso comunicativo experimental y religioso. 


\section{4.}

\section{Un proceso comunicativo experimental y religioso}

La novelista pone de relieve el proceso comunicativo basado en el intercambio lenguajero. En efecto, indica que vivimos en un mundo de intercomunicación que no excluye la coexistencia entre lenguaje y pensamiento. En Suerte Mulana, hay pocos diálogos que informan sobre el valor de la expresión libre del pensamiento que, a su vez, permite contestar, de manera correcta, a todo contexto inédito. En otros términos, la comunicación entre adultos y jóvenes abre a un campo de infinitas posibilidades de creaciones. Las buenas relaciones entre Violeta y los miembros de su entorno social, católico y musulmán, revela el poder de la razón puesta al servicio del bienestar individual y colectivo. La joven española toma conciencia de la evolución del tiempo y la dialéctica de la angustia y la esperanza suscitada por la paradoja de la condición humana marcada por la muerte y la voluntad de eternidad. A partir del proceso educativo basado en la comunicación experimental, el abuelo le enseña a Violeta cómo funciona la naturaleza. El viejo empieza su formación con la relación que existe entre los objetos animados e inanimados y hace resaltar la importancia del fuego, el aire, el agua y la tierra, sin olvidar las diferentes combinaciones entre el calor y el frío. Demuestra que son elementos que favorecen el bienestar y el malestar del ser humano, aunque no puede separarse de ellos. Indica, además, que la existencia se caracteriza por el hecho de que la vida es movimiento y que todo contiene una forma de soplo vital. Para él, este soplo es el motor del dinamismo existencial. De ahí, la vida es dinámica y resulta de una organización que el ser humano no debe destruir. Esta concepción de la vida es la base de la profunda relación amistosa entre la cristiana Violeta y la musulmana Aixa:

El padre de Aixa aseguraba que cuando algo se desea con mucha intensidad, si es con sentimiento limpio y bueno, es como si se viera en realidad. Convencidas de ello, acordaron la manera de estar juntas sin que nadie se enterase y sin tener que 
infringir las normas: Aixa rompería la tela por una esquina de la Jaime sin que nadie lo notara. De este modo, Violeta podría entrar por allí cuando quisiera. Sólo hacía falta la fuerza de su mente y la bondad de su corazón (Alvarado, 2002: 58-59).

La importancia del deber correctamente hecho por los padres y tutores que se preocupan por la educación de los niños y jóvenes es otro pilar de la novela de María Jesús Alvarado. En efecto, Suerte Mulana nos propone una definición del deber como un orden de realidad caracterizado por lo permitido y lo prohibido. Mejor dicho, el hecho de educar a una persona, como lo hacen tanto el abuelo de Violeta como el padre de Aixa, consiste en procurarles costumbres caracterizadas por un conjunto de buenas reglas de vida. Mediante las acciones del abuelo o del padre, vemos que el educador orienta al joven hacia la posibilidad de escoger lo bueno respecto a la autonomía de la voluntad ante lo malo, sobre todo a nivel de las relaciones humanas interculturales. Además de la perspectiva pacífica del proceso educativo, cabe señalar, en la novela, un vistazo a la sostenibilidad. En efecto, la escritora española insiste en el conocimiento de los riesgos que corre la sociedad humana al no tener en cuenta los recursos de la tierra. El respeto del mar por parte de los personajes y la harmonía entre los nómades saharauis en el desierto demuestran que la novela remite a un vocabulario de la naturaleza vista como pura, sin ninguna contaminación debida al ser humano:

Notaba que todas volvían alegres, satisfechas de lo hermosos que estaban sus camellos y la buena leche que daban sus cabras, después de haber encontrado buenos pastos allá donde las nubes, instrumentos de Alá, bendecían la tierra [...]. Adultos y niños compartían el mismo mundo, el mismo trabajo y las mismas satisfacciones: ordenar las cabras, recoger la Jaima, buscar agua [...]. Violeta no podía evitar un cierto sentimiento de envidia por esa vida libre, en armonía con los demás y con el cielo y la tierra (Alvarado, 2002: 56-57). 
Violeta actúa para respetar el medio ambiente como lo ha enseñado su abuelo. A través de estos personajes, la novela no hace referencia a un entorno destruido por la contaminación. Invita más bien a una contemplación y respeto del medio ambiente cuyos recursos no son explotados por una sociedad de consumo, sino por gente que lo explotan para sacar lo necesario sin gastar o agotar las reservas de la tierra. Es un mensaje educativo sobre la sostenibilidad hacia los jóvenes (Rodríguez, 2004: 205-208). Otro eje de la novela es la religión como fuente educativa. Eso se justifica porque el comportamiento de los jóvenes españoles y saharauis puede apoyarse en una moralidad en consonancia con las leyes divinas. Es decir que Dios interviene como una causa moral que no excluye un paralelismo entre fe y libre albedrío en el vivir cotidiano. Desde entonces, la novelista desempeña un papel de escritora cristiana preocupada por la educación juvenil (Aldama, 2000) y nos muestra un personaje determinado por su entorno sociocultural, pero que no está condicionado como si fuera máquina. Sin embargo, aunque es católica, la escritora no establece escalas entre las religiones en la medida en que el cristianismo y el islam no se enfrentan. El párrafo siguiente es una prueba del retorno a la convivencia en Al-Ándalus, aunque muchos historiadores rechazan el concepto de coexistencia pacífica en aquella época (Sánchez, 2016):

El mes de mayo, como todo el mundo sabe, es el mes de la Virgen. Violeta se sentía orgullosa cuando le tocaba poner las flores a la imagen que había en el altarcillo de la clase. Las niñas musulmanas que quisieran podían participar y siempre había unas cuantas que no querían perderse nada; les encantaba rezar y entonaban divertidas y hasta devotas cada una de las canciones. A Violeta, siempre queriendo ser justa, le pareció necesario corresponderles haciendo ellas, las cristianas, algo propio de la religión islámica (Alvarado, 2002: 35-36).

La experiencia cultural, según la novelista, corresponde a una etapa fundamental de la educación a través de dos perspectivas. En la primera, vemos que el joven se siente profundamente enraizado en las tradiciones que hace resaltar la pertenencia cultural 
del individuo, $y$, en la segunda, se destaca un conjunto de creencias individuales que son frutos de la subjetividad de cada individuo (Guzmán, 2003: 40). Esta doble característica de la novela demuestra que la educación del joven pasa por un sistema de creencias articuladas, por una parte, alrededor de textos sagrados que son la Biblia y el Corán y, por otra parte, de un conjunto de otros ritos culturales. En efecto, observamos que la religión remite, a la vez, primero, a la comunidad a la que pertenecen los cristianos y musulmanes, y segundo, a la creencia a la cual adhiere Violeta cuando va a iglesia y Ahmed cuando lee el Corán. Todos utilizan su tiempo libre para reforzar sus lazos interculturales; lo que es una estrategia fundamental para vincular un mensaje sobre los diferentes métodos de educación.

\section{5. \\ Conclusión}

María Jesús Alvarado combina creatividad literaria y mensaje sobre el fondo sociocultural del territorio saharaui para abordar la cuestión educativa. Revela cómo el fenómeno educativo sirve de puente para que el joven sepa manejar el concepto de libre albedrío y de respeto al otro. El interés del estudio reside en el hecho de que, aunque la autora se inspire en muchos eventos reales, se destaque cierto idealismo porque, mediante la novela, la escritora aspira a un mundo abierto donde se realiza el "melting pot", fuente de progreso.

\section{Bibliografía}

\section{Libros}

Alvarado, M.J. (2002). Suerte Mulana. Las Palmas de Gran Canaria: Puentepalo.

Cárdenas, C. (1995). Guía para la educación intercultural con jóvenes. Madrid: Consejería de Educación y Ciencia. 
Carrasco González, A. (2009). La novela colonial hispanoafricana: las colonias africanas de España a través de la historia de la novela. Madrid: Sial.

Paillé, P., Mucchielli, A. (2012). L'analyse qualitative en sciences humaines et sociales. Paris: Armand Colin.

Sánchez Saus, R. (2016). Al-Ándalus y la Cruz. La invasión musulmana de Hispania. Barcelona: Stella Maris.

\section{Monografía de un solo autor}

Ferronato, J. (2000). Aproximaciones a la globalización, $2^{\text {a }}$ ed. Bogotá: Macchi.

\section{Artículos en una obra colectiva}

Maestre Hernández, A. (2003). "Educar para construir una nación”, en A.B. Espina Barrio (coord.). Emigración e integración cultural, 109-142. Salamanca: Universidad de Salamanca.

Rodríguez Marín, F. (2004). "La educación ambiental y los jóvenes”, en F.V. de Castro González (coord.). Teoría y práctica de la educación ambiental, 205-208. Granada: Grupo Editorial Universitario.

\section{Artículos y comunicaciones}

Guardiola Bono, M.J. (2003). "La educación religiosa de una mujer ilustrada”, Revista de Historia Moderna, 21, 365-382.

Guzmán Maya, S.M., Arias Betancur, Y.F. (2009). "La educación religiosa escolarizada", Revista Páginas, 89, 33-48.

Montaño Muñoz, J.L., Montano Muñoz, J.C. (2008). “Apuntes para una lectura católica de la educación como formación a partir de la experiencia personal del amor", Revista Páginas, $81,35-51$.

Nájera, O. (2007). "Los nuevos imaginarios religiosos de los jóvenes", Revista de Antropología experimenta, 7, 142-152.

Pérez Esclarín, A. (2006). "El mundo de los jóvenes desafía a la educación”, Revista educación en valores, 3/4/6, 8-28.

Ripoll Saíz, A. (2006). "El adolescente en la literatura juvenil actual”, Primeras noticias, 217, 71-78. 
Tébar Belmonte, L. (2017). "La educación y formación de la conciencia moral de los jóvenes”, Foro educacional, 29, 133-145.

\section{Tesis de doctorado}

M'Beirik, A.A. (2015). El nacionalismo saharaui. De Zemla a la organización de la unidad africana, Las Palmas de Gran Canaria: Universidad de Las Palmas de Gran Canaria.

\section{Referencias electrónicas}

Aldama Roy, A.M. (2000). "Los autores cristianos ante la educación de los jóvenes", [en línea], <http://www.anmal.uma.es/numero6/Aldama.htm $>$ [26.04.2018].

Moya, C. (2011). "La cuestión saharaui y su recepción en la literatura española”, [en línea], <http://www.hazloquedabas.blogspot.com> [7.05.2018]. 